\title{
PENANAMAN MANGROVE DI PERAIRAN PANTAI TANJUNG BASTIAN
}

\author{
Ludgardis Ledheng1), Maria Yustiningsih') \\ Program Studi Pendidikan Biologi, Fakultas Ilmu Pendidikan, \\ Universitas Timor, Indonesia ${ }^{1,2}$ \\ Pos-el: Ludgardisledheng12@gmail.com ${ }^{1)}$
}

\begin{tabular}{|l|l|l|} 
Dikirim: 14 Juli 2018 & Direvisi: 10 Agustus 2018 & Diterbitkan: 29 Agustus 2018 \\
\hline
\end{tabular}

\begin{abstract}
ABSTRAK
Wilayah pesisir Pantai Tanjung Bastian mempunyai peranan penting bagi pembangunan sebab menyediakan sumber daya alam dan jasa lingkungan yang potensial ditinjau dari aspek ekologi, ekonomi, dan pariwsata. Luas hutan mangrove di Kabupaten Timor Tengah Utara pada tahun 2005 adalah 323,26 ha berkurang menjadi 298,26 ha pada tahun 2008. Hutan mangrove Pantai Tanjung Bastian memiliki luas lebih kurang 37 ha. Jumlah tersebut mengalami penurunan dari tahun ke tahun (Anonimous, 2005). Hal ini disebabkan karena banyaknya pemanfaatan hutan mangrove untuk berbagai keperluan diantaranya areal pertambakan, keperluan pemenuhan kayu bakar dan bahan bangunan untuk kepentingan sendiri dan komersial, infrastruktur pantai termasuk pelabuhan, pembangunan tempat perdagangan dan perumahan, pengembangan pariwisata yaitu wisata alam serta pertanian. Berbagai aktivitas yang terjadi pada hutan mangrove Tanjung Bastian memberikan dampak kurang baik terhadap vegetasi, di antaranya terjadi perubahan komposisi dan struktur vegetasi pada berbagai tingkat pertumbuhan seperti anakan, pancang, tiang, dan pohon. Tujuan kegiatan pengabdian ini adalah: 1) Pemberdayaan masyarakat untuk selayaknya menjaga populasi mangrove yang ada di pesisir pantai tanjung Bastian. 2) Menumbuhkan kesadaran dan motivasi bagi masyarakat pesisir untuk menanam kembali mangrove sebagai bentuk kepedulian terhadap lingkungan pesisir. Metode kegiatan yang digunakan dalam kegiatan ini adalah penyuluhan dan pendampingan penanaman mangrove. Hasil kegiatan yang didapat bahwa setelah dilakukan penyuluhan tentang potensi dan bahaya kerusakan ekosistim mangrove, masyarakat merasa sangat antusias melakukan penanaman bersama. Dampak dari kegiatan ini adalah mulai ditanamnya manggrove khusunya pada areal tambak.
\end{abstract}

Kata kunci: mangrove, penanaman, pesisir, tanjung, Bastian 


\section{ABSTRACT}

The areal of Tanjung Bastian beach has important role to the development for its natural resources and environmental service which is potential seen from echological aspect, economic, and tourism aspect. The wide area of mangrove forest in North middle of Timor Regency in 2005 is 323,26 ha less and become 298,26 in 2008. Mangrove forest of Tanjung Bastian Beach has the wide of less than 37 ha, the amount has seen decrease year to year (Anonimous, 2005). It is caused by mangrove forest usage of countless number for various needs such as for fishing pool, the need of fire wood fulfilment and building material for individual need and trade, seach building including harbour, the built of comercial place and residence, the development of tourism, such as natural tourism and agriculture. Various activity which happened in mangrove forest of Tanjung Bastian give had effect to the vegetation such as there in composition change and vegetation structure to the various level of growthness, such as (anakan, pancang, tiang) and tree. The aim of this study is: 1) Societal development to keep mangrove population which are in the area of Tanjung Bastian beach. 2) To grow the awereness and motivation to the society of the beach to grow back mangrove as a solidarity to the beach environment. The method of activity used in this activity is socialization and accompanience of mangrove plantation. The result of the activity got is that after the socialization of potential and the dangerous of echosystem damage of mangrove, the society felt enthusinostic to grow mangrove. The effect of this activity is mangrove is began to be growth specialty in the fishing pool area.

Key words : mangrove, plantation, seaside, tanjung, Bastian

\section{PENDAHULUAN}

Wilayah pesisir Pantai Tanjung Bastian mempunyai peranan penting bagi pembangunan sebab menyediakan sumberdaya alam dan jasa lingkungan yang potensial ditinjau aspek ekologi, ekonomi dan pariwsata. Luas hutan mangrove di Kabupaten Timor Tengah Utara pada tahun 2005 adalah 323,26 ha berkurang menjadi 298,26 ha pada tahun 2008. Hutan mangrove Pantai Tanjung Bastian memiliki luas lebih kurang 37 ha, jumlah tersebut mengalami penurunan dari tahun ke tahun (Anonimous, 2005). Hal ini disebabkan karena banyaknya pemanfaatan hutan mangrove untuk berbagai keperluan diantaranya areal pertambakan, keperluan pemenuhan kayu bakar dan bahan bangunan untuk kepentingan sendiri dan komersial, infrastruktur pantai termasuk pelabuhan, pembangunan tempat perdagangan dan perumahan, pengembangan pariwisata yaitu wisata alam serta pertanian. Berbagai kegiatan dan kerusakan yang terjadi pada hutan mangrove Tanjung Bastian 
memberikan dampak kurang baik terhadap vegetasi, diantaranya terjadi perubahan komposisi dan struktur vegetasi pada berbagai tingkat pertumbuhan seperti anakan, pancang, tiang dan pohon.

Komposisi dan struktur vegetasi hutan dapat menjadi dasar untuk memprediksi kemungkinan perubahan lingkungan yang akan terjadi di masa depan (Aumeeruddy, 1994). Menurut Bengen (2011) kerusakan dan gangguan pada strata pertumbuhan dapat menjadi kendala pada proses regenerasi pohon mangrove di masa yang akan datang. Salah cara untuk mengetahui dan mempelajari keberadaan jenis - jenis pada lokasi ekosistem mangrove yang ada di Tanjung Bastian adalah melalui studi analisis mangrove (Snedaker and Snedaker, 1984).

Hasil studi thesis tentang "Analisis Vegetasi" pada tahun 2008 di perairan Tanjung Bastian diperoleh bahwa mangrove mayor dan mangrove asosiasi mengalami kerusakan (Ledheng, 2008). Bila ditinjau secara kasat mata, kondisi bakau pada perairan Tanjung Bastian sekarang, masih tidak mengalami perubahan ke arah pertumbuhan dan peningkatan populasi. Hal ini disebabkan tidak adanya kesadaran masyarakat untuk mengetahui pentingnya kelestarian mangrove. Oleh karena itu dipandang perlu adanya tindakan nyata melalui penanaman mangrove sebagai upaya konservasi alam di Pantai Tanjung Bastian.

\section{METODE}

a. Penyuluhan

Penyuluhan dilakukan oleh dosen pelaksana kegiatan pengabdian dibantu oleh kepala Desa, tokoh mayarakat dan tokoh adat.

b. Pendampingan teknis penanaman

Pendampingan teknis penanaman dilakukan dengan cara sebagai berikut:

Penanaman mangrove untuk jenis bakau dilakukan dengan dua cara yaitu penanaman langsung (direct planting) dilakukan dengan menanam langsung propagul di lapangan dan tidak langsung (indirect planting) dilakukan dengan persemaian terlebih dahulu benih/propagul dan setelah berumur kurang lebih 3 bulan baru ditanam di lapangan. Penanaman mangrove asosiasi berupa asam ditanam dalam bentuk anakan. 


\section{HASIL DAN PEMBAHASAN}

Mangrove di Pantai Tanjung Bastian tumbuh pada daerah intertidal yaitu daerah pantai yang dipengaruhi pasang surut seperti tersaji pada Gambar 1.

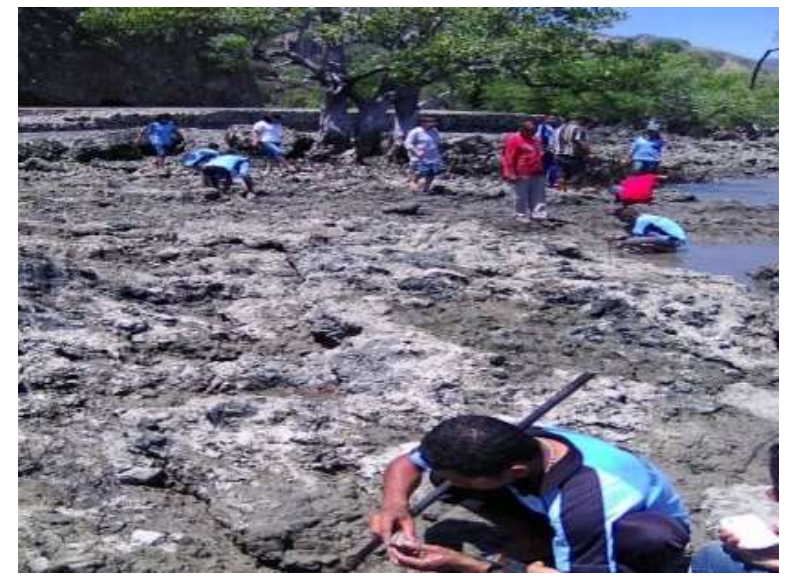

Gambar 1: Kondisi mangrove di Pantai Tanjung Bastian

Kegiatan yang dilaksanakan di antaranya:

\section{a. Penyuluhan}

Untuk melaksanakan kegiatan penanaman tim pelaksana pengabdian terlebih dahulu melakukan penyuluhan. Yang dijadikan prioritas untuk terlaksananya kegiatan ini adalah tokoh masyarakat, tokoh adat dan pemerintah setempat. Kehadiran beberapa tokoh masyarakat dan pemerintah dalam hal ini Bapak Lurah Humusu Wini, sebagai bentuk peran aktif dalam melaksanakan penyuluhan bersama tim pengabdian untuk memberikan kesadaran bagi masyarakat. Kegiatan penyuluhan bersama Bapak Lurah Humusu Wini dapat dilihat pada Gambar 2.

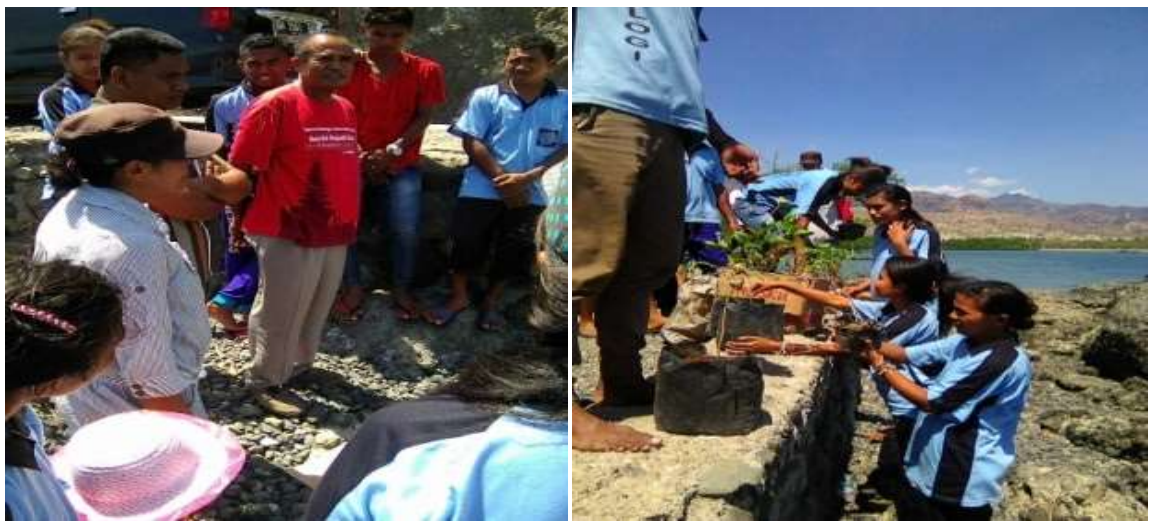

Gambar 2: Penyuluhan pada masyarakat di pesisir pantai. 
Penyuluhan dilakukan melalui 2 (dua) bagian yakni penjelasan pentingnya manggrove dan bahaya kerusakan oleh Bapak Lurah sedangkan teknis rehabilitasnya dilakukan oleh tim dosen pengabdi dari Universitas Timor bersama masyarakat pesisir pantai Tanjung Bastian.

\section{b. Pendampingan Penanaman}

Tahapan pelaksanaan penanaman mangrove di perairan pantai Tanjung Bastian: 1) Pengumpulan anakan mangrove. Pengumpulan anakan mangrove dari jenis Rhizophora sp yang mempunyai tipe buah vivipar (benih berkecambah di atas pohon). Benih ini dapat ditanam secara langsung.

2) Penanaman langsung dengan propagul yaitu penanaman secara langsung tanpa melalui tahap persemaian (tanpa anakan). Cara penanaman ini pada umumnya digunakan pada jenis-jenis dari family Rhizophoraceae yang mempunyai propagul/benih yang panjang. Propagul Rhizophora seperti terlihat pada Gambar 3.

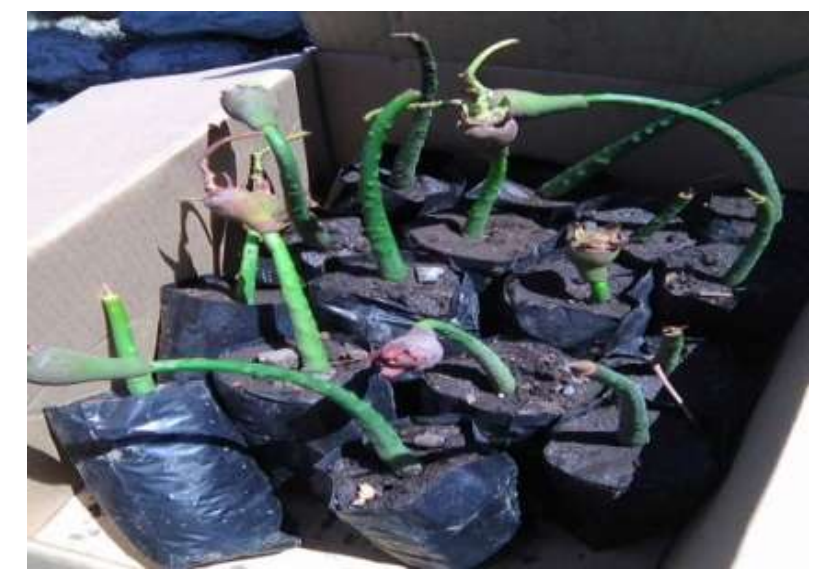

Gambar 3: Propagul rhizophora

3). Perlakuan infuse pada tanaman mangrove asosiasi (tanaman asam/ Tamarindus indica,L). Tanaman asam yang merupakan mangrove asosiasi di tanam di daerah supratidal (daerah daratan) yang langsung berbatasan dengan jalan raya. Untuk mencukupi ketersediaan air supaya dapat bertahan hidup maka dilakukan perlakuan infis pada tanaman asam, seperti terlihat pada Gambar 4 . 

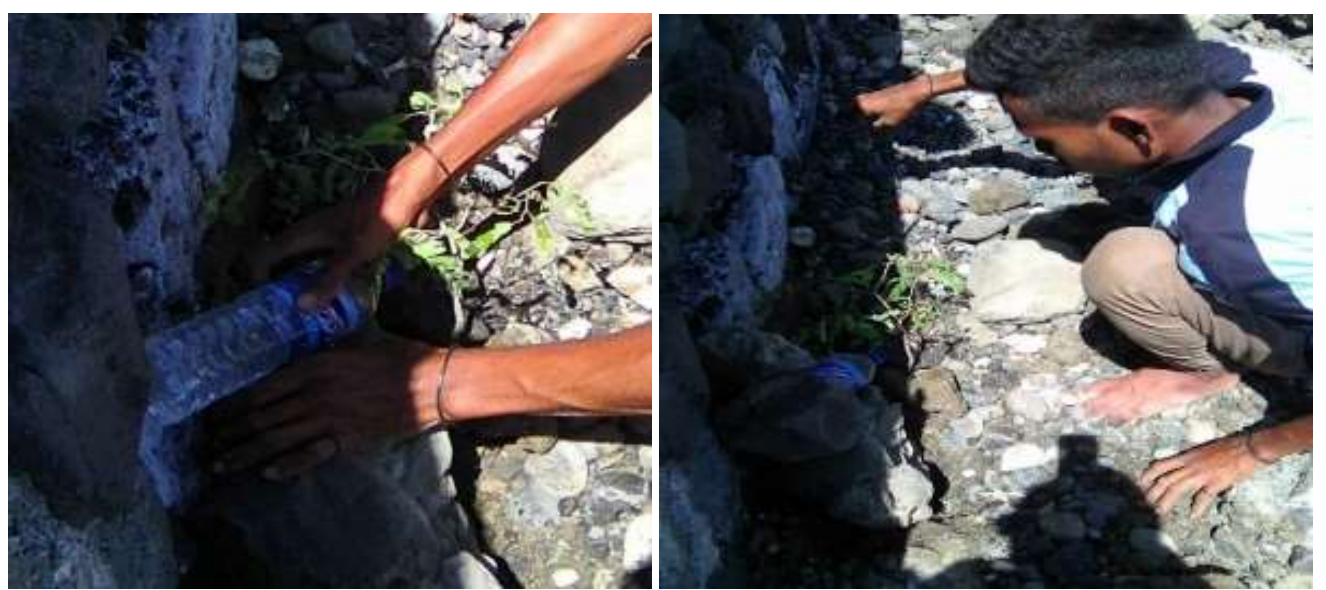

Gambar 4: Perlakuan infus pada tanaman mangrove asosiasi

4). Penanaman dengan anakan dilakukan pada jenis Avicenia sp dan Soneratia sp. Cara penanaman anakan yaitu menggunakan penanaman alam dan penanaman menggunakan anakan berasal dari persemaian yang ditumbuhkan pada polybag. Penanaman jenis Avicenia sp dan Soneratia sp dapat dilihat pada Gambar 5.
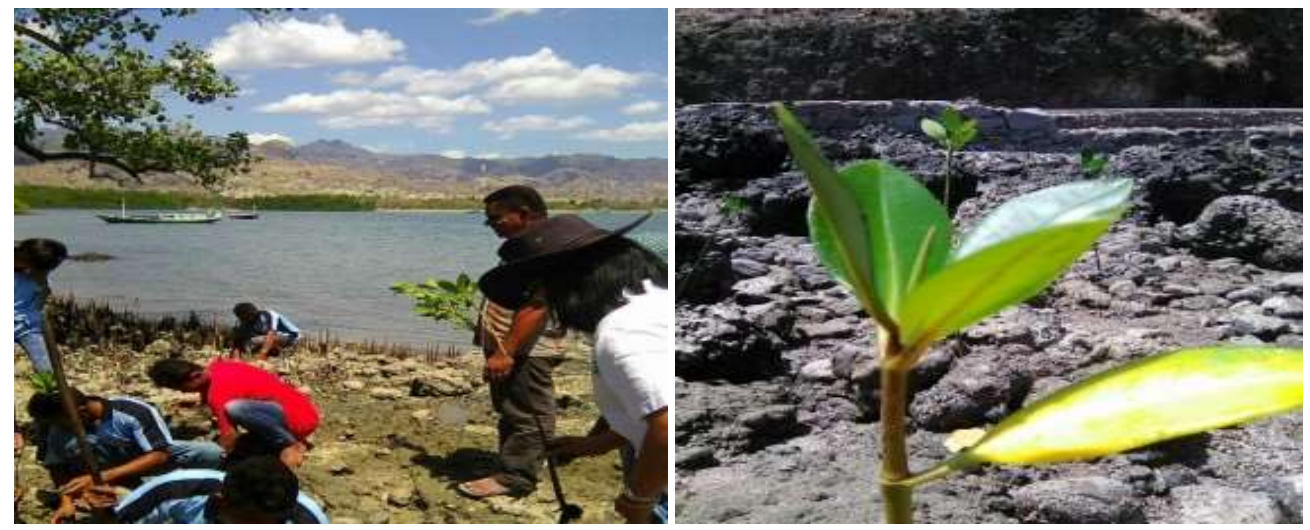

Gambar 5: Penanaman mangrove jenis Avicenia sp dan Soneratia sp

\section{SIMPULAN}

Kegiatan pengabdian ini telah dilakukan dan diperoleh beberapa kesimpulan diantaranya: 1) Masyarakat merasa penting melakukan penanaman mangrove hal ini ditunjukkan dengan mulai menanam manggrove pada areal tambak. 2) Masyarakat diperkenalkan beberapa jeni manggrove dan antusias melakukan persemaian terutama jenis mangrove asisiasi. Misalnya Tanaman Asam (Tamarindus indica,L). 


\section{UCAPAN TERIMA KASIH}

Terlaksananya kegiatan ini tidak terlepas dari bantuan dan kerja sama beberapa pihak di antaranya: Universitas Timor yang telah memberikan bantuan dana untuk terlaksananya kegiatan; Lembaga Penelitian dan Pengabdian Universitas Timor sebagai fasilitator terlaksananya kegiatan pengabdian ini; Bapak Lurah Humusu Wini yang telah aktif berpartisipasi hingga terlaksananya penanaman mangrove; dan Masyarakat pesisir Pantai Tanjung Bastian yang sudah aktif menjaga dan melestarikan populasi mangrove.

\section{DAFTAR PUSTAKA}

Anonimous, 2005. Timor Tengah Utara Dalam Angka. Pemerintah Kabupaten Timor Tengah Utara. Kefamenanu. Provinsi Nusa Tenggara Timur.

Aumeeruddy, Y. 1994. Local Representation and Management of Agroforests on thePeriphery of Kerinci Seblat National Park, Sumatra, Indonesia, People andPlants Working Paper 3. Paris. UNESCO.

Bengen. 2001. Pengenalan dan Pengelolaan Ekosistem Mangrove. Pusat Kajian Sumberdaya Pesisir dan Lautan. Penerbit IPB. Bogor.

Dahuri, J. Rais Sapta P.G. dan M.J. Sitepu. 2001. Pengelolaan Sumber Daya Wilayah Pesisir Dan Lautan Secara Terpadu, PT.Pradnya Paramitha. Jakarta.

Khazali, M. 1999. Panduan Teknis: Penanaman Mangrove bersama Masyarakat. Wetlands International - Indonesia Programme, Bogor.

Ledheng, 2009. Komposisi dan Struktur Mangrove di Pantai Tanjung Bastian, Kabupaten Timor Tengah Utara, Propinsi Nusa Tenggara Timur. Program Pasca Sarjana S2, Universitas Udayana. Denpasar.

Nybakken, 1992. Biologi Laut Suatu Pendekatan Ekologis. Penerbit PT. Gramedia, Jakarta. Penerjemah Eidmenn dkk. 